\title{
Entre a democracia e a verdade: Laclau e o populismo
}

\author{
Camila Batista ${ }^{1}$
}

Resumo: Este ensaio pretende problematizar a teoria do populismo de Ernesto Laclau (1935-2014) diante dos frequentes tratamentos caricatos do termo que acabam por reduzi-lo a uma espécie de ameaça generalizada ao campo político. Laclau delimita o terreno democrático no qual uma construção não essencialista do político como populismo se inscreve utilizando, para tanto, ferramentas retóricas. Neste sentido, a relação entre populismo e democracia será abordada de duas maneiras: primeiramente, considerando as interpretações mais recentes de Nadia Urbinati (2019) e Pierre Rosanvallon (2020) e, em seguida, a partir do conceito de "parresía", presente nos dois últimos cursos de Michel Foucault (1926-1984) no Collège de France. A retórica aparece como uma característica constitutiva da má parresía e, ao mesmo tempo, como a possibilidade oferecida por Laclau da significação do povo e do social como objetos coerentes. Neste contexto, buscaremos explicar como o populismo, situado entre a democracia e a verdade, pode ser considerado sinônimo de má parresía e quais os reflexos desta caracterização na teoria do populismo de Ernesto Laclau.

Palavras-chave: populismo - democracia - parresía - discurso

\section{Between democracy and truth: Laclau and the populism}

\begin{abstract}
This essay aims to problematize the theory of populism by Ernesto Laclau (1935-2014) in the face of the frequent caricature of the term that ends up reducing it to a kind of generalized threat to the political field. Laclau delimits the democratic terrain in which a non-essentialist construction of the political as populism is inscribed using, for this purpose, rhetorical tools. In this sense, the relation between populism and democracy will be approached in two ways: first, considering the most recent interpretations by Nadia Urbinati (2019) and Pierre Rosanvallon (2020), and then, based on the concept of "parresía", present in the two last courses by Michel Foucault at the College de France. Rhetoric appears as a constitutive characteristic of "bad parresía" and, at the same time, as the possibility offered by Laclau of the inscription of the people and the social as coherent objects. In this context, we will try to explain how populism, situated between democracy and truth, can be considered synonymous with "bad parresía" and what are the reflexes of this characterization in Ernesto Laclau's theory of populism.
\end{abstract}

Keywords: populism - democracy - parresía - discourse

\footnotetext{
${ }^{1}$ Doutoranda pelo programa de pós-graduação do P Programa de Pós-Graduação em Filosofia da Pontifícia Universidade Católica do Paraná (PGF-PUCPR, Curitiba) e pelo Dottorato in Scienze Umane dell'Università degli Studi di Ferrara (Itália). Bolsista CAPES/PROSUC. E-mail: camila.batista@pucpr.edu.br.
} 
O populismo integra teorias das mais diversas abordagens, tendo se tornado comum utilizar o termo quando não se sabe ao certo do que se fala: seja de um movimento espontâneo, violento, anti status quo, baseado nas ideias de um líder demagogo ou, então, para reforçar o caráter "favoritário" de políticas em prol da população, etiqueta comum de governos de esquerda principalmente da América Latina. No entanto, esta série de características que podem ser atribuídas ao conceito acabam por constituir um objeto opaco e por vezes paradoxal. Nos últimos quinze anos, desde a publicação de $A$ raz̧ão populista (2005), o nome de Ernesto Laclau é recorrente nas reflexões sobre o populismo. Concordamos, desde logo, com Laclau ao compreender o "populismo" como uma forma de construção do político, reforçando com o autor as críticas às leituras levianas do termo.

Por "político" nos referimos à organização do campo comum de disputas sociais, que relacionam povo e Estado tanto a partir das instituições quanto da ação popular direta. O populismo é, assim, uma das formas do político de construir relações. Outro aspecto a ser afirmado de antemão é que o populismo é uma forma de construção do político em um regime democrático, ou seja: a garantia de formação de um movimento popular de caráter político é dependente de um regime que não exclua parte da população. Se seus métodos são de fato democráticos, teremos a oportunidade de discuti-lo durante este ensaio.

Ao mesmo tempo, essas questões devem ser direcionadas ao problema específico que buscamos resolver: quais as consequências de reduzir o populismo a uma espécie de "caricatura" que põe a questão no limite da racionalidade? Acreditamos que o conceito foucaultiano de parresía pode nos ajudar a dissolver algumas das definições negativas comumente atribuídas ao populismo. O modo como a verdade de um discurso compõe o sujeito que fala e o sujeito que com ele está relacionado no jogo parresiástico diz muito sobre como o sujeito diz a si mesmo. Neste sentido, se o populismo é uma manifestação irracional ou violenta, podemos afirmar que o sujeito diz a si mesmo desta forma, ou devemos questionar se o problema é que o próprio jogo parresiástico compromete, de antemão, o sujeito? A segunda opção será nosso alvo de interpretação, particularmente a partir da distinção entre boa e má parresía, presente na primeira hora da aula de $1^{\circ}$ de fevereiro de 1984 de Coragem da Verdade. Se a retórica é parte de uma má parresía, o populismo na perspectiva de Laclau, não sendo definível de maneira literal e, ao mesmo tempo, sendo dependente de figuras de linguagem, configura-se como má parresía. No entanto, boa ou má, a parresía é um dizer verdadeiro: não se pode retirar o critério de verdade da relação, podese questionar os argumentos utilizados para justificá-lo. É o que pretendemos fazer.

\section{O populismo nos limites da democracia}

Para esclarecer a que nos referimos quando falamos de uma "interpretação caricata" do populismo, é preciso levar em consideração a crítica de Laclau aos textos sobre o populismo, publicados entre 1960 e $1990^{2}$. Sua crítica é direcionada a uma espécie de incompetência em compreender o populismo que acaba, por vezes, reduzindo-o a uma "ameaça" oferecida pelo povo enquanto ator político, uma vez que esteja organizado sem a mediação estatal ou nos limites de um sindicato ou partido, por exemplo. As tentativas de

${ }^{2}$ Cf. LACLAU, Politics and Ideology in Marxist Theory: capitalism, fascism, populism, pp. 133-199; LACLAU, A razão populista, p. 33-56.

: : : Cadernos de Ética e Filosofia Política | Número 38 (1) | $1^{\circ}$ semestre de 2021 | Página 238 : : : 
submeter o conceito a fenômenos dissímeis tornou-se o próprio empecilho na busca de uma definição coerente para o termo. Ao analisar estas posições, Laclau abandona uma concepção de populismo "acoplado" à luta de classes para a afirmação deste como uma estratégia de construção do político. Privilegiaremos a segunda definição. Para tanto, é preciso esclarecer a centralidade da teoria do discurso para a teoria política de Laclau.

O principal objetivo de $\mathrm{Laclau}^{3}$ é investigar como se constituem as identidades coletivas, tema abordado em Hegemony and Socialist Strategy (1985), primeiramente, como compreensão da lógica do social a partir da afirmação da impossibilidade da sociedade. Em outras palavras, a teoria do discurso recusa qualquer hipótese que a priori defina o campo social. Sendo assim, o conceito de "hegemonia" é apresentado como a hipótese estratégicopolítica de formação das relações sociais nas quais as demandas (demands) se "equivalenciam" para construir, segundo os princípios do projeto democrático radical - baseado em uma ação política não-violenta - a sociedade como objeto discursivo ${ }^{4}$. Neste sentido, em Hegemony and Socialist Strategy Laclau afirma a impossibilidade da sociedade como totalidade racionalmente compreensível, afirmando que uma formação social é construída por relações antagônicas que estão em constante deslocamento. É a partir desta teoria que em A rąão populista é possível pensar a formação do "povo" como plebs que visa ascender a um populus; em outras palavras, um grupo equivalenciado busca hegemonizar o poder, trocando o foco da questão de "impossibilidade da sociedade" para a problemática do "povo" como ator político em construção.

Em Hegemony and Socialist Strategy, Laclau e Mouffe utilizam a "lógica da equivalência" (um "senso de solidariedade", em primeiro momento, que une diferentes demandas contra um inimigo comum) e a "lógica da diferença" (oposta à equivalência, afirma a singularidade de uma demanda) para demonstrar como a variação nas relações é capaz de subverter as fronteiras sociais e, para tanto, consideram como a menor unidade de sua análise a "demanda". Neste sentido, a recusa do "essencialismo" aparece como afirmação do campo aberto do social, pois somente considerando as demandas como unidades menores é que se torna possível pensar em relações diferentes em cada caso e indetermináveis fora destas relações: uma demanda equivalenciada está diretamente relacionada com outras, constituindo o locus de uma possível contra-hegemonia; uma demanda em sua diferença está diretamente em relação de exclusão com uma formação equivalencial e, ainda que negativamente, faz parte de uma relação e é definida por ela 5 .

Acerca da especificidade das demandas, Laclau as separa em duas categorias: a demanda democrática, que é uma petição particular de um grupo (democraticamente isegórica) e a demanda popular, formada através da lógica da equivalência pela "solidarização" e pelo posterior laço libidinal que conecta parte da população ${ }^{6}$. Para Laclau, as demandas populares constituem um "povo" como ator político: o populismo não é uma "parte" a ser representada por uma classe dirigente, mas aparece como

\footnotetext{
${ }^{3}$ LACLAU, A razão populista, p. 25.

${ }^{4} \mathrm{O}$ foco da teoria da democracia radical é, tendo como horizonte de compreensão a teoria do discurso, construir o político de acordo com as demandas sociais e, abandonando algumas e renovando outras estratégias políticas, compreender a "sociedade" como resultado das relações antagônicas que, quanto mais aparecem, mais democrático tornam o campo social.

${ }^{5}$ LACLAU; MOUFFE, Hegemonia e Estratégia Socialista: por uma política democrática radical, p. 204-213.

${ }^{6}$ LACLAU, A razão populista, p. 98.
} 
uma possibilidade distintiva e sempre presente de estruturação da vida política. Uma aproximação ao populismo em termos de anormalidade, desvio ou manipulação é estritamente incompatível com nossa estratégia teórica. ${ }^{7}$

Para aprofundar a discussão sobre o tema, apresentaremos, brevemente, duas recepções da teoria de Laclau: a de Nadia Urbinati em Me the People (2019) e a de Pierre Rosanvallon em Le Siécle Du Populisme (2020). Urbinati busca demonstrar de que modo o populismo "desfigura" a democracia, não por se tratar de um regime totalitário ou fascista, mas porque não segue uma espécie de "padrão" clássico democrático, apesar de utilizar ferramentas democráticas para seu desenvolvimento. A autora nos oferece uma origem da teoria do povo como "mal" governar a cidade, argumentando que um governo de muitos é corruptível e incapaz de atingir consenso. A autora afirma que a aparição de governos neoliberais trouxe consigo uma espécie de "empreitada antipopular" que favorece o distanciamento do governo em relação ao povo devido ao receio de uma denominação populista, culminando em uma tendência a descaracterizar o processo democrático de participação popular como elemento democrático legítimo. A teoria de Urbinati permanece próxima à de Laclau na medida em que não recusa o populismo como hipótese de formação do político, mas se afasta deste ao fazer referência a uma estrutura democrática a ser "deformada".

Por sua vez, Rosanvallon opera em um registro diferente de Urbinati, ainda que também ofereça uma origem histórica para o termo: com um objetivo similar ao de Laclau, alega que as interpretações (inclusas as de Mouffe e Laclau) estão, de alguma forma, "contaminadas". Seu objetivo é esboçar aquilo que "falta" a uma compreensão "essencial" do populismo, com a ambição de fazê-lo em termos que permitam uma confrontação que vai "à raiz das coisas". Isso significa reconhecer o populismo como a ideologia ascendente do século XXI, reconhecimento necessário para a instrução de uma crítica aprofundada no terreno da crítica democrática social ${ }^{9}$. No entanto, ao considerar o populismo uma "ideologia", Rosanvallon reduz o populismo e entra em conflito com a crítica de Laclau a definições desta espécie. Enumerando características e procurando "algo a mais", as leituras tanto de Urbinati quanto de Rosanvallon coincidem justamente naquilo que Laclau compreendeu como o uso limitado de uma ferramenta, conferindo a fenômenos novos aspectos caros a teorias antigas.

\section{O falar franco nos limites do populismo}

Concordamos com Urbinati ao afirmar que uma noção "negativa" de governo popular não é estranha à história da filosofia política. A exclusão de uma parte do social é, segundo Laclau, a condição para que uma sociedade discursivamente construída faça sentido, pois o "limite do social deve se dar no interior do próprio social, como algo que o subverte (...)" "10. Sendo assim, podemos partir de dois pressupostos: o primeiro é que uma noção "negativa" do social não impede a compreensão da parte excluída como parte e o segundo é

\footnotetext{
${ }^{7}$ LACLAU, A razão populista, p. 27.

${ }^{8}$ URBINATI, Me the People: how populism transforms democracy, p. 139.

${ }^{9}$ ROSANVALLON, Le siècle Du populisme: histoire, théorie, critique, p. 17.

${ }^{10}$ LACLAU; MOUFFE, Hegemonia e Estratégia Socialista..., p. 204.
} 
que o significado dado a esta "parte" é que precisa ser alterado, já que é indispensável para a compreensão da lógica do social. É neste sentido que o conceito de parresía pode nos oferecer um diálogo interessante com a teoria de Laclau. O conceito foucaultiano que pode ser traduzido com a expressão "dizer verdadeiro" é tema dos dois últimos seminários de Michel Foucault (1926-1984) no Collège de France, sendo abordado primeiro em Le Gouvernement de Soi et des Autres (1983) em relação direta com a democracia grega e, posteriomente, em Le courage de la vérité (1984), voltado para a relação entre parresía e ethos ${ }^{11}$. Enfatizaremos um argumento específico deste último, presente no início da primeira hora da aula de $1^{\circ}$ outubro de 1983.

Foucault faz um breve levantamento sobre a compreensão do termo ao longo da história, tanto na prática grega quanto na instituição religiosa, chegando até a contemporaneidade com a prática médica" ${ }^{12}$ Segundo Foucault, a parresía "é etimologicamente a atividade que consiste em dizer tudo: pan rêma, Parresiàzesthai é 'dizer tudo'. O Parresiastés é aquele que diz tudo" "13. Há, no entanto, duas qualificações ${ }^{14}$ principais para o termo: uma "negativa" e uma "positiva" - que serão referidas como "boa" e "má" parresía. A "boa” parresía "consiste em dizer a verdade, sem dissimulação nem reserva nem cláusula de estilo nem ornamento retórico que possa cifrá-la ou mascará-la (...) Não ocultar nada, dizer as coisas verdadeiras é praticar a parresía"15. Esse "dizer tudo" coloca em risco aquele que fala, comprometendo-o com sua verdade. Por outro lado, a "má" parresía

Consiste em dizer tudo, no sentido de que se diz qualquer coisa (qualquer coisa que passe pela cabeça, qualquer coisa que possa ser útil à causa que se defende, qualquer coisa que possa servir à paixão ou ao interesse que anima quem fala). O parresiasta se torna e aparece então como o tagarela impenitente, como aquele que não sabe se conter ou, em todo caso, como aquele que não é capaz de indexar seu discurso a um princípio de racionalidade e a um princípio de verdade. ${ }^{16}$

Reconhecemos a semelhança com a ocorrência histórica da crítica à democracia, já apresentada por Urbinati - ao se referir ao "falar franco" negativo, Foucault remonta à crítica à democracia grega e a

má cidade democrática, aquela que é totalmente diversificada, deslocada, dispersa entre interesses diferentes, paixões diferentes, indivíduos que não se

\footnotetext{
11 Acerca da relação específica entre parresía e democracia, cf. FONSECA, "Os paradoxos entre a democracia e o dizer-verdadeiro"; CANDIOTTO, "Parrhesía filosófica e ação política: Platão e a leitura de Foucault"; GROS, Foucault: a coragem da verdade.

12 “O estatuto desse outro é variável (...) seu papel, sua prática, não é tão mais fácil de isolar, de definir, já que, por certo lado esse papel cabe à pedagogia, se apoia nela, mas também é uma direção de alma. Pode ser também uma espécie de conselho político. Mas igualmente esse papel se metaforiza, e talvez até se manifeste e tome forma numa espécie de prática médica, já que é do cuidado da alma que se trata e da determinação de um regime de vida, regime de vida que comporta, está claro, o regime das paixões, mas também o regime alimentar, o modo de vida sob todos os seus aspectos" (FOUCAULT, A coragem da verdade: o governo de si e dos outros II, p. 7). ${ }^{13}$ FOUCAULT, $A$ coragem da verdade: o governo de si e dos outros $I I$, p. 10.

${ }^{14}$ FONSECA, "Os paradoxos entre a democracia e o dizer-verdadeiro", p. 19.

${ }^{15}$ FOUCAULT, $A$ coragem da verdade: o governo de si e dos outros II, p. 11.

${ }^{16}$ FOUCAULT, $A$ coragem da verdade: o governo de si e dos outros II, p. 11.
} 
entendem. Essa má cidade democrática pratica a parresía: todos podem dizer qualquer coisa. ${ }^{17}$

Uma aproximação à relação entre a verdade e a cidade pode ser encontrada em Barros $^{18}$, que nos oferece uma reflexão acerca do "efeito parresiástico" e da sua capacidade de mudança na subjetividade tanto daquele que fala quanto daquele que escuta.

Barros afirma que a relação entre dynasteia (relação político-agonística) e isegoreia (igualdade de todos) influencia diretamente a maneira como um movimento popular pode ser compreendido. Fazendo referência à teoria de Laclau, ele afirma que, se o populismo consiste em uma reorientação de valores e constituição de novas identidades populares, essas novas demandas surgem em um espaço que não é considerado "seu" para dizê-lo, pois apesar de todos poderem falar, nem todos podem dizer a verdade. Segundo Barros, o discurso verdadeiro não é dividido igualmente porque a "aparição" do populismo assume um caráter "extraordinário" no tecido social, tornando a isegoria democrática uma falácia ao diferenciar entre comum e incomum uma ocorrência política. Se, segundo Foucault,

a parresía é, em duas palavras, a coragem da verdade naquele que fala e assume o risco de dizer, a despeito de tudo, toda a verdade que pensa, mas é também a coragem do interlocutor que aceita receber como verdadeira a verdade ferina que ouve ${ }^{19}$,

então afirmar que o populismo é algo extraordinário que pretende somente expor uma visão de mundo diferente significa, por um lado, limitar seu intuito de tomar a hegemonia (como direção) da comunidade política, porque de antemão o movimento é visto como danoso em relação à ordem social estabelecida e, por outro, negar o "jogo parresiástico" relacional que exige o comprometimento de ambas as partes. A única relação possível entre populismo e comunidade, neste caso, é a de uma "ameaça", que irrompe e perturba a ordem "comum".

A reflexão de Barros introduz o tema da má parresía a partir da questão "quem pode dizer a verdade?". Por outro lado, nós assumimos que, boa ou má, "parresía” se refere a um dizer verdadeiro, dando preferência a possíveis consequências que tal distinção pode gerar. Sendo assim, é preciso levar em conta um fator decisivo tanto na distinção entre boa e má parresía quanto para a teoria do populismo de Laclau: a retórica.

Como a análise de Foucault em Coragem da Verdade é voltada especificamente para a parresía no mundo grego e seu significado pensado em relação a textos platônicos, o contraste com a retórica - ferramenta sofista criticada intensamente por Platão por sua falta de compromisso com a verdade ${ }^{20}$ - define, segundo Candiotto, o limite do dizer verdadeiro, pois a retórica "é considerada a técnica cujos procedimentos têm por finalidade persuadir e convencer aqueles para os quais está dirigida. Configura discurso performativo que prescinde da convicção daquele que enuncia em relação ao conteúdo da enunciação" ${ }^{21}$. Sendo assim,

\footnotetext{
${ }^{17}$ FOUCAULT, $A$ coragem da verdade: o governo de si e dos outros II, p. 12.

18 BARROS, "No todo El mundo puede decir la verdad. Foucault, la parrhesía y El populismo", p. 256.

${ }^{19}$ FOUCAULT, $A$ coragem da verdade: o governo de si e dos outros II, p. 13.

${ }^{20}$ A crítica aos sofistas pode ser encontrada ao longo das obras platônicas como, por exemplo, o Crátilo, o Sofista, o Górgias e a discussão estética presente no Livro X da República.

${ }^{21}$ CANDIOTTO, "Parrhesía filosófica e ação política: Platão e a leitura de Foucault", p. 33.
} 
uma má parresía contaria com aspectos retóricos, "maculando" a verdade do parresiastés incapaz de comprometer-se com suas próprias palavras.

Neste sentido, o problema de uma reflexão sobre o populismo nos moldes da retórica clássica - como "mera retórica" ou ainda "tagarelice" - torna a compreensão da movimentação popular um problema de puro protesto. O uso de "utilitarismos" a favor de si e de sua causa, como descritos por Foucault ${ }^{22}$, reduz a meras expressões caricatas e irrelevantes de irracionalidade quaisquer movimentos populares que questionem as relações de poder.

Sendo assim, Laclau não se refere à retórica ${ }^{23}$ como a um instrumento persuasivo sem critério de verdade, mas como a possibilidade de, através de figuras como a catacrese e a sinédoque ${ }^{24}$, nomear algo que literalmente não pode ser nomeado - a referência aos jogos de linguagem wittgensteinianos exclui uma concepção da linguagem como "rotuladora" das $\operatorname{coisas}^{25}$. A retórica é, para a teoria do populismo laclausiana, aquilo que permite deslocar de um conceito o seu sentido unívoco e retirar ${ }^{26}$, com esse movimento, qualquer resquício de essencialismo que possa estar inscrito em uma relação política. Em outras palavras, Laclau faz uso da retórica para afirmar um campo político em constante mudança, responsivo a definições que visam "reduzir" demandas a um espaço pré-determinado.

Quando aplicamos a esta lógica uma noção de retórica clássica que focaliza a herança filosófica que enfatiza a verdade como pré-requisito para a compreensão de um discurso, percebemos que a crítica de Foucault à persuasão retórica envolve um problema que não contempla a teoria de Laclau - não porque não haja necessidade de verdade na teoria do discurso, mas porque o registro de verdade parresiástico não coincide necessariamente com o da retórica. Laclau afirma que a significação do povo como ator político depende das figuras de linguagem, e somente a partir destas é que seu significado pode ser compreendido, invertendo a lógica de determinação prévia entre "boa" ou "má" parresía. O caráter retórico ou ainda pejorativo atribuído ao parresiastés da demanda popular limita seu espaço a uma relação de antemão excludente: não há, portanto, outro espaço para o populismo em uma leitura parresiástica senão o da má parresía.

\section{Considerações finais}

Em O sujeito e o poder (1980) Foucault afirma que é preciso, primeiro, ter consciência histórica da situação presente para uma conceituação adequada, e, em seguida, verificar o

\footnotetext{
22 FOUCAULT, $A$ coragem da verdade: o governo de si e dos outros II, p. 10-11.

${ }^{23}$ LACLAU, A razão populista, p. 119-121.

24 “Ocorre um deslocamento retórico toda vez que um termo literal é substituído por um termo figurativo (...) na retórica clássica, um termo figurativo que não pode ser substituído por um termo literal era denominado de catacrese (por exemplo, quando falamos da 'perna da cadeira'). Este argumento pode ser generalizado se aceitarmos o fato de que qualquer distorção do significado possui, em sua raiz, a necessidade de expressar algo que o termo literal simplesmente não transmitiria (...) a construção do povo é, essencialmente, catacrética. (...) em uma relação hegemônica, uma diferença particular assume a representação de uma totalidade que a excede. Isso confere uma clara centralidade a uma figura particular no arsenal da retórica clássica: a sinédoque (a parte que representa o todo)." (LACLAU, A razão populista, p. 121). O papel da retórica na teoria de Laclau é expandido na obra The Retorical Foundations of Society, publicado em 2013, discussão que excede o objetivo do presente ensaio.

${ }^{25}$ LACLAU, A rąão populista, p. 115.

${ }^{26}$ LACLAU, A raz̃ão populista, p. 171.
} 
tipo de realidade com a qual se está lidando. Partindo de uma análise voltada às relações de poder sob o ponto de vista daquele que é oprimido e não daquele que oprime, afirma que a pluralidade de resistências tem em comum o não confinamento a "uma forma política e econômica particular de governo", objetivando o efeito do poder enquanto tal (aquilo que ele causa), questionando quem nós somos:

(estas lutas) são uma recusa a estas abstrações, do estado de violência econômico e ideológico, que ignora quem somos individualmente, e também uma recusa de uma investigação científica ou administrativa que determina quem somos. $^{27}$

Neste sentido, o caráter relacional do poder é capaz de demonstrar como a inscrição do sujeito em um determinado discurso influencia o modo como este aparece na construção do social. Vimos com Barros ${ }^{28}$ que o limite entre aquele que pode dizer a verdade e aquele que não pode é definido por estas relações. A "má cidade", que aparece em Coragem da verdade como "diversa e cheia de paixões diferentes" 29 , onde todos podem falar e dizer qualquer coisa é sinônimo de má parresía e, consequentemente, seus atores são, por esta definição, maus.

Em Laclau, no entanto, este é o campo do discurso em seu pluralismo e radicalidade; há algo mais democrático do que aceitar as oposições? Ou ainda, há que aceitar algo quando, em última instância, o que se tem de fato são somente diferenças? $O$ erro consiste na distinção entre o aceitável (uma verdade não retórica, que diz tudo e assume para si o risco de fazê-lo) e o inaceitável (uma verdade passional, sem constituição necessariamente racional, retórica, persuasiva). Se a má parresía não configura risco àquele que dela faz uso, é porque mesmo que seja verdade aquilo que se diz, segundo a própria definição de Foucault, não se está de fato em uma relação que corre risco de mudança; para que haja de fato uma mudança, é preciso coragem por parte do parresiastés e quem se disponha a ouvir a verdade, culminando na mudança da relação entre ambos. Sendo assim, além da má parresía reduzir moralmente um discurso com as características mencionadas (persuasão, retórica, tagarelice), reduz sua coerência a uma oratória sem função, incapaz de demandar uma mudança. Temos, portanto, dois problemas: o primeiro, é que ainda que a retórica laclausiana inverta o uso de termos da retórica clássica, ao utilizar a ferramenta foucaultiana de leitura da má parresía temos, de qualquer forma, uma crítica a um apelo passional e persuasivo e, em segundo lugar, se o populismo não é boa parresía, então ele é somente um fenômeno que permanece no campo do incompreensível como uma "falha" no tecido político.

Tentar interpretar o populismo através do conceito foucaultiano de parresía acaba por caracterizá-lo como má parresía. A retórica é, neste caso, elemento indispensável para a formação do social como objeto compreensível, já que "sociedade" ou "povo" não são conceitos ou ainda objetos que contêm em si papéis definíveis. Isso reduz o populismo não somente a uma "caricatura", lendo-o muitas vezes como ideologia ou "irrupção irracional" de um povo à margem, mas na mesma medida impede uma movimentação popular de ter qualquer papel que não o de ameaça à "totalidade coerente da política", se compreendida

${ }^{27}$ FOUCAULT, O sujeito e o poder, p. 232-5.

${ }^{28}$ BARROS, "No todo El mundo puede decir la verdad. Foucault, la parrhesía y El populismo", p. 255.

${ }^{29}$ FOUCAULT, A coragem da verdade: o governo de si e dos outros II, p. 11. 
como racionalmente definível. Em resumo, se a má parresía e a retórica são traços de um parresiastés que não tem compromisso com a verdade e não toma risco algum ao fazê-lo, ele não pode ser tomado como igual na isegoria democrática e muito menos oferecer uma solução viável para os problemas da comunidade, negando a possibilidade da assunção hegemônica do poder pelo movimento popular.

\section{Referências bibliográficas}

BANG, Henrik Paul. Foucault's political challenge: from hegemony to truth. United Kingdom: Palgrave Macmillan, 2015.

BARROS, Sebástian. "No todo El mundo puede decir la verdad. Foucault, la parrhesía y El populismo”. In: Las Torres de Lucca, no 11, Julio-Deciembre: 253-284, 2017.

CANDIOTTO, César. "Parrhesía filosófica e ação política: Platão e a leitura de Foucault". In: Rev. Filos., Aurora, Curitiba, v. 23, n. 32, p. 31-52, jan/jun. 2011.

FONSECA, Marcio A. "Os paradoxos entre a democracia e o dizer-verdadeiro". In: Rev. Filos., Aurora, Curitiba, v. 23, n. 32, p. 17-30, jan/jun. 2011.

FOUCAULT, Michel. O sujeito e o poder. In: DREYFUS, Hubert L.; RABINOW, Paul. Uma trajetória filosófica: para além do estruturalismo e da hermenêutica. Tradução: Vera Porto Carrera. Rio de Janeiro: Forense Universitária, 1995, p. 231-250.

- A coragem da verdade: o governo de si e dos outros II. Curso do Collège de France (19831983). Trad. Eduardo Brandão. São Paulo: Martins Fontes, 2011, p. 3-62.

GROS, Frédéric (org.). Foucault: a coragem da verdade. Tradução de Marcos Marcionilo. São Paulo, Parábola Editorial, 2004.

LACLAU, Ernesto; MOUFFE, Chantal. Hegemonia e Estratégia Socialista: por uma política democrática radical. Brasília: Editora Intermeios, 2015.

LACLAU, Ernesto. Politics and Ideology in Marxist Theory: capitalism, fascism, populism. London: NLB, 1977.

- A razão populista. Tradução de Carlos Eugênio Marcondes de Moura. São Paulo: Três Estrelas, 2013.

ROSANVALLON, Pierre. Le siècle Du populisme: histoire, théorie, critique. Paris: Éditions Du Seuil, 2020.

URBINATI, Nadia. Me the People: how populism transforms democracy. Cambridge, Massachusetts: Harvard University Press, 2019. 